\title{
Formation of classes of urban environment areas for their renovation
}

\author{
Sergei Matreninskiy ${ }^{1, *}$, Valeriy Mischenko ${ }^{1}$, and $V$. Chertov ${ }^{1}$ \\ ${ }^{1}$ Voronezh State Technical University, 20-let Oktyabrya str., 84, 394006, Voronezh, Russia
}

\begin{abstract}
The article considers the classification of both compact built-up development areas of cities and populated localities, and the objects included into the scope of these territories: buildings, urban structures, utilities, etc. At the $1^{\text {st }}$ stage, we suggest to form clusters out of the urban environment areas, and also property items located on the territories considered with the following uniform characteristics used: depreciation, obsolescence, level of technical comfort of territories and objects determined as per the special methodological procedure. At the $2^{\text {nd }}$ stage, we suggest to group the separate construction objects located at the territories considered: residential buildings, utilities, etc. into clusters based on space-planning, engineering, structural and other one-type characteristics. The set of territorial clusters, which are formed based on a number of uniform characteristics, will make it possible to assure sustainable planning of retrofitting and renovation of urban environment areas by using standard organizational and management solutions, construction machines, repair and reconstruction methods for uniform clusters.
\end{abstract}

\section{Introduction}

The compact built-up development areas (CBDA) of cities and populated localities are the essential elements of human living and life support environment and are aimed at the implementation of the top-priority social need in decent dwelling with the proper infrastructure.

The lack of decent dwelling with the well-developed municipal infrastructure and utilities is the issue of national security of Russia, a number of other countries, the source of continuous social strain in the extremely non-uniform society, the hurdle for returning to normal demographic situation, the hurdle for dynamic and successful development and existence of the country in the global community.

Thus, the issue of CBDA renovation, including the housing facilities, utilities, road and transport infrastructure and other elements of urban built-up areas, needs to be solved immediately to bring all CBDA facilities into compliance with the state-of-the-art standards and requirements.

\footnotetext{
*Corresponding author: gso09@yandex.ru
} 


\section{Justification of systematic approach to be used for classification of compact built-up development areas}

The approach to solving of such issues, which include multiple different factors (residential and public buildings, water supply and water discharge networks, heat supply systems, roads, parks, public gardens, etc,), which have their own peculiarities of existing and evolving, should be based on the system analysis method successfully used in urban development projects, and also in technology and arrangement of construction and reconstruction of facilities in cities and populated localities [1 - 9].

When planning the CBDA renovation based on systematic approach, two major design issues should be solved: 1. Selection of such arrangement of CBDA as a system, which will assure the complete and proper system representation (modeling) of these areas (system synthesis problem), and 2. Justification of such parameters values of elements and objects of the system in whole (parametric synthesis problem), which will meet the requirements specified - decent housing and living conditions.

The methodological approach to solving of the first problem - systematic representation of CBDA - is described in detail in a number of papers with its elements, general and specific objects formed, and with external environment factors indicated [10,11, 12]. The papers justify CBDA modeling as a multilevel hierarchical system - a system complex city-planning formation $(\mathrm{CPF})$ interacting with the external environment. The detail structure of $\mathrm{CPF}$ is given in Figure 1.

To solve the $2^{\text {nd }}$ problem, based on the developed system representation of CBDA as a $\mathrm{CPF}$, the development and functioning performance indicators have been established for specific objects, general objects, separate elements and CPF in whole, which include the level of technical comfort (TC), obsolescence and depreciation $(\mathrm{O}, \mathrm{D})$, and also their parameters assuring the housing and living conditions for population of these territories in accordance with the current requirements $[10,12-15]$.

\section{Basis of classification of compact built-up development areas as per development and functioning performance indicator - level of technical comfort}

The technical comfort level of a city-planning formation is the convenience of technical arrangement of living environment of the society, which is evaluated by the degree of its compliance with the sanitary and hygienic standards, safety regulations and rules of this environment and other indicators established, when necessary, by the qualified professionals - experts.

When introducing the notion of TC, we suggest to determine it based on combined profile of obsolescence and depreciation [6, 12, 15]. Papers [12 - 18] describe the detailed methodological approach to determination of the level of technical comfort, depreciation and obsolescence of CPF and its components, and also to formation and synthesis of sustainable activities aimed at their reconstruction and renovation.

The next stage of evolution of decision-making methods used for renovation of CBDA in the form of CPFs is laying of the groundwork for CPF classification as per the serviceability and safety indicators as well as based on the set of consumer properties, including spaceplanning, environmental and hygienic, structural and technological, architectural and aesthetic properties of $\mathrm{CPF}$, its components, general and specific objects $[6,19]$.

In the abovementioned papers, it is suggested to evaluate CPF with their further classification based on the most common indicator - the level of technical comfort, which 
can be used for qualitative characterization of the current CPF condition and CPF condition in forecastable future.

The CPF classification is, first and foremost, needed to increase the efficiency of making of organizational, technological and managerial decisions on renovation of urban territories. The classification proposed is built on considering the entire compact built-up development area as a set of CPFs, which are characterized by different values of the technical comfort level falling within certain variation ranges.

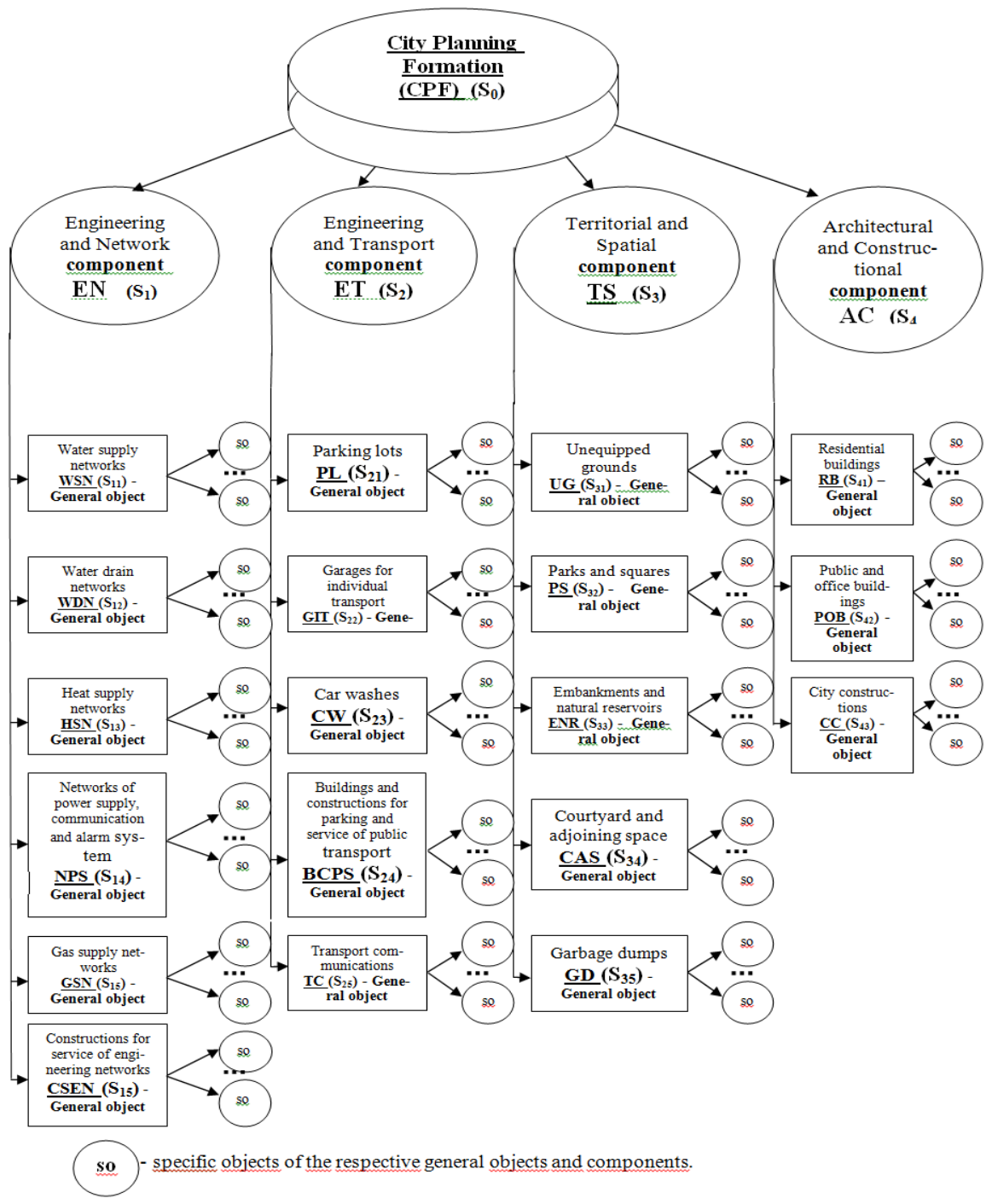

Fig. 1. The objective structure of the city planning formation as a system including its components and objects.

The proximity of TC indicators for CPFs of one class may be the evidence of similar deterioration condition of CPF components and objects, which will promote the use of type designs when adopting construction, organizational and technological solutions while preparing the operations for reconstruction and renovation of $\mathrm{CPF}$, the introduction of flowline method of work performance to reduce the time and cost of reconstruction. 
It is suggested to divide CPF sets into classes by using private methods in accordance with Figure $2[6,19]$.

1. Method of division of large-scale residential development areas into separate CPFs according to their natural borders: roads, tree belts, water barriers, etc. to obtain certain breakdown variant $\mathrm{m}$, which includes a set of $\mathrm{n} C P F$ units, where $n=\overline{1, N} 1 \mathrm{~m}$

2. Method for determination of obsolescence of $\mathrm{CPF}$, its components, general and specific obiects.

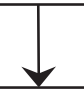

3. Method for determination of depreciation of $\mathrm{CPF}$, its components, general and specific objects.

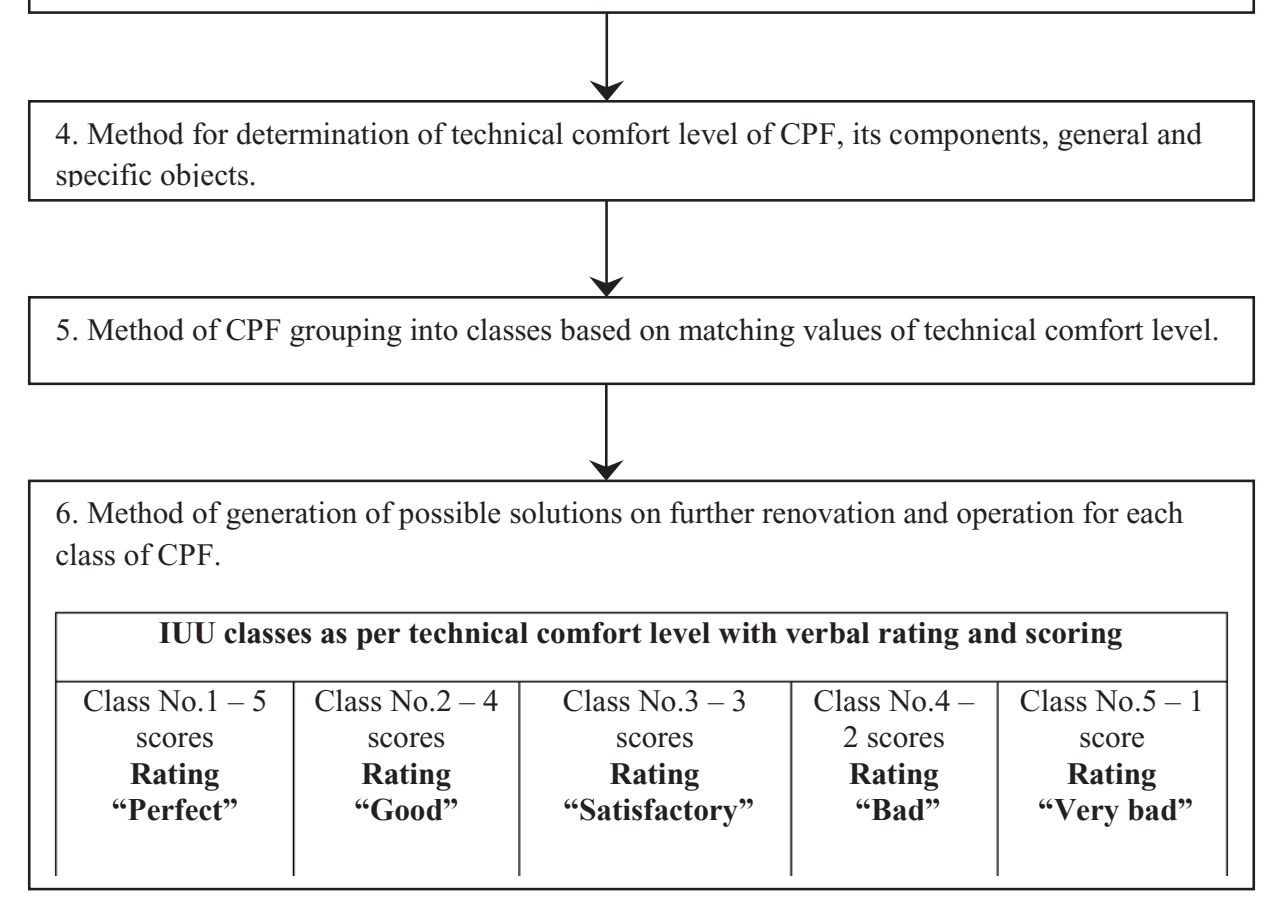

Fig. 2. Flow chart of methodological approach to evaluation and classification of compact built-up development areas.

The CPF classification system developed with the use of Harrington verbal-numerical scale [20] allows forming of CPF classes based on numerical, verbal and score estimate of their levels of technical comfort.

However, this classification system assures mainly the qualitative assessment of condition of separate segments of CBDA represented by CPFs, the identification of low-level improvement of some CPFs and relative well-being of others. The evaluation of technical comfort level of separate CPFs determines only the degree of compliance or non-compliance of CBDA condition with the state-of-the-art requirements and standards, i.e. existing problems in overall improvement of urban development areas considered, without focusing 
on particular CPF components and objects, which form the total low or high rating. This system of CPF classification is of extremely general nature, as the classification indicator technical comfort level (TC) - is a function of multiple variables due to hierarchic nature of the system of CPF components and objects performance indicators being arguments $\mathrm{D}$ and $\mathrm{O}[10,13,14,21]$ :

$$
\mathrm{TC}=[1-\mathrm{f}(\mathrm{D}, 0)] \cdot 100 \%
$$

where D - integral index of CPF depreciation; $\mathrm{O}$ - integral index of CPF obsolescence.

The CPFs and their components need to be classified based on a wider list of indicators, which will allow the creation of a system for considering and grouping of both CPFs and components included into CPFs, general and specific objects into classes as per different features fully characterizing the current $\mathrm{CPF}$ condition in an unbiased manner.

Forming of classes, which include multiple CPF objects as per the similarity of certain features and their variation ranges, will allow the use of different work performance variants when planning the renovation of territories housing these objects with the application of onetype organizational and technological solutions, materials, structures, machines and equipment, repair and reconstruction methods.

\section{Classification of cpf and its components as per degree of depreciation and obsolescence, technical, engineering and other uniform characteristics}

It is suggested to develop a system of classifiers allowing the detailed evaluation of condition of CPFs and their components under consideration as per both level of technical comfort and depreciation and obsolescence of CPFs, their components, general and specific objects.

It is advisable to break down CPFs, their components, general and specific objects into D and O-based classes with a set of methods used, see Figure 2, where CPFs and their components will be grouped into classes based on matching scores of $\mathrm{D}$ and $\mathrm{O}$ values.

The system of classified elements obtained will be summarized in a set of tables, the left column of which will contain an object of classification - CPF, components, general objects, specific objects differing in TC, D, and $\mathrm{O}$ values - see Table 1 .

Table 1. Classification of CPFs and their elements as per level of technical comfort, depreciation and obsolescence.

\begin{tabular}{|c|c|l|}
\hline $\begin{array}{c}\text { Object of } \\
\text { classification }\end{array}$ & $\begin{array}{c}\text { Classification features } \\
\text { (subject of } \\
\text { classification) }\end{array}$ & \multicolumn{1}{|c|}{$\begin{array}{c}\text { Result of } \\
\text { classification }\end{array}$} \\
\hline $\begin{array}{c}\text { CPFs, components, } \\
\text { general objects, specific } \\
\text { objects }\end{array}$ & TC & $\begin{array}{l}\text { Forming of classes of CPFs, } \\
\text { components, general and specific } \\
\text { objects differing in TC values. }\end{array}$ \\
\hline $\begin{array}{c}\text { CPFs, components, } \\
\text { general objects, specific } \\
\text { objects }\end{array}$ & D & $\begin{array}{l}\text { Forming of classes of CPFs, } \\
\text { components, general and specific } \\
\text { objects differing in D values. }\end{array}$ \\
\hline $\begin{array}{c}\text { CPFs, components, } \\
\text { general objects, specific } \\
\text { objects }\end{array}$ & O & $\begin{array}{l}\text { Forming of classes of CPFs, } \\
\text { components, general and specific } \\
\text { objects differing in O values. }\end{array}$ \\
\hline
\end{tabular}

The values of TC, D and $\mathrm{O}$ indicators fall within 5 full-scale ranges of Harrington scale [20] - see Table 2. 
Table 2. Harrington scale used for evaluation of technical comfort level, depreciation and obsolescence.

\begin{tabular}{|l|c|c|}
\hline \multicolumn{1}{|c|}{ Verbal rating } & Scoring & Numerical estimate \\
\hline $\begin{array}{l}\text { "Perfect" for TC } \\
\text { or "Very bad" for D and O }\end{array}$ & 5 & $0.8-1$ \\
\hline $\begin{array}{l}\text { "Good" for TC } \\
\text { or "Bad" for D and O }\end{array}$ & 4 & $0.63-0.8$ \\
\hline "Satisfactory" for TC, D and O & 3 & $0.37-0.63$ \\
\hline $\begin{array}{l}\text { "Bad" for TC } \\
\text { or "Good" for D and O }\end{array}$ & 2 & $0.2-0.37$ \\
\hline $\begin{array}{l}\text { "Very bad" for TC } \\
\text { or "Perfect" for D and O }\end{array}$ & 1 & $0-0.2$ \\
\hline
\end{tabular}

It is also suggested to additionally classify specific objects as per technical and operating indicators, which include deterioration of separate elements and utilities, structural, materials-related, space-planning and other uniform characteristics of specific objects, as well as technical and engineering solutions on reduction of depreciation and obsolescence of objects under consideration.

The developed branched classifier or a set of classifiers containing the continuously updated database will make it possible to form different clusters of CPFs, their components, general and specific objects grouped as per uniform characteristics: TC, D and O; and for specific objects - based on a number of additional above-mentioned indicators. Thus, the objective is to classify a number of CPFs, components and objects based on multiple variables.

To carry out such multi-dimensional classification of CPFs and their components under consideration, it is necessary to specify the condition of all specific objects included into CPF: residential buildings, public buildings, water supply systems, water discharge systems, roads, parks, quays, etc. It is advisable to update or re-compile the register of specific objects being the parts of CPFs under consideration with the indication of their current condition as per TC, D and $\mathrm{O}$, as well as based on the number of above-mentioned technical and operating indicators.

Upon specification of CPF classification results, the list of CPFs with low TC values and high $\mathrm{D}$ and $\mathrm{O}$ values respectively should be prepared according to the form given in Table 1 .

The CPFs identified above should be accepted for the top-priority renovation and reconstruction. Specific objects with the highest $\mathrm{D}$ and (or) $\mathrm{O}$ values shall be selected out of $\mathrm{CPF}$ accepted. For specific objects with high $\mathrm{D}$ and (or) $\mathrm{O}$ values, we need to determine a feasible reconstruction activity, technical and engineering solutions required to implement this activity, all of which will assure the planned transformation of the objects to higher TC condition. The methodological approach to solving of this problem is described in detail in a number of papers $[10,16,18]$.

Then, we break down $\mathrm{D}$ and $\mathrm{O}$ into constituent factors determining their value for each specific objects selected. For D, it can be depreciation of separate structural units (foundations, walls, roofing, etc.). For $\mathrm{O}$ - factors characterizing the gap between the consumer properties of the objects and the state-of-the-art requirements and standards: irrelevant space-planning and structural solutions, engineering solutions, etc. $[13,14]$.

These factors will be determining features for forming of classes of specific objects with similar D of separate structural units and (or) $\mathrm{O}$ characterized by certain values of noncompliance of some consumer properties with the established standards and current requirements. Apart from $\mathrm{D}$ and $\mathrm{O}$, other technical, structural and operating indicators can be selected as classification features.

Thus, a number, a set of clusters is created. Furthermore, a separate specific object can fall into several clusters depending on the values of its $\mathrm{D}$ and (or) $\mathrm{M}$ and the values of 
technical, structural and operating indicators. For example, the following basic classification features can be used for classification of specific objects - residential buildings with increased D and (or) O: certain structural elements and parts of building with significant D graded in specific ranges; certain obsolescence factors - gap to environmental parameters, architectural parameters, etc.

A number of representative classification features are summarized in a single table, each line of which is a result of measurement of features considered at each object examined. For example, Table 3 shows a set of initial data for forming of clusters of residential buildings based on appearance and condition of a structural element - foundation. The following indicators are taken as initial data: $X_{\mathrm{k} 1}$ - material of foundation and its type (reinforced concrete strip foundation, reinforced concrete post foundation, pile foundation, etc.); $\mathrm{X}_{\mathrm{k} 2}-$ depreciation of foundation in certain ranges in accordance with Harrington scale [20]; $\mathrm{X}_{\mathrm{k} 3}-$ possible technical solution for foundation repair and underpinning (by casing, cement grouting, bored injection piles, etc.). Here, $\mathrm{k}$ takes on a value from 1 to $\mathrm{n}$.

Table 3. Initial data for forming of clusters of residential buildings based on foundation appearance and condition.

\begin{tabular}{|c|c|c|c|}
\hline $\begin{array}{c}\text { Residential } \\
\text { building (RB) }\end{array}$ & $\begin{array}{c}\text { Material and type } \\
\text { of foundation }\end{array}$ & $\begin{array}{c}\text { Depreciation of } \\
\text { foundation }\end{array}$ & $\begin{array}{c}\text { Technical solution } \\
\text { of foundation } \\
\text { repair }\end{array}$ \\
\hline $\mathrm{RB}_{1}$ & $\mathrm{X}_{11}$ & $\mathrm{X}_{12}$ & $\mathrm{X}_{13}$ \\
\hline $\mathrm{RB}_{2}$ & $\mathrm{X}_{21}$ & $\mathrm{X}_{22}$ & $\mathrm{X}_{23}$ \\
\hline $\boldsymbol{\cdots}$ & $\boldsymbol{\cdots}$ & $\boldsymbol{\cdots}$ & $\mathbf{- \cdot}$ \\
\hline $\mathrm{RBn}$ & $\mathrm{X}_{\mathrm{n} 1}$ & $\mathrm{X}_{\mathrm{n} 2}$ & $\mathrm{X}_{\mathrm{n} 3}$ \\
\hline
\end{tabular}

Table 4 shows a set of initial data for forming of clusters of residential buildings with significant obsolescence in the form of irrelevant space-planning structure of residential building, including the following: $X_{\mathrm{k} 1}$ - year of construction; $X_{\mathrm{k} 2}-$ space-planning solution of building (sectional, corridor-type, gallery-type, combined); $\mathrm{X}_{\mathrm{k} 3}$ - material and structure of partitions (brick, gypsum plaster board, etc.); $X_{\mathrm{k} 4}$ - gap to the current space-planning requirements expressed, for example, in scores and determined by judgment-based method. Here, $\mathrm{K}$ takes on a value from 1 to $\mathrm{m}$.

Table 4. Initial data for forming of clusters of residential buildings based on their space-planning structure.

\begin{tabular}{|c|c|c|c|c|}
\hline Residential & $\begin{array}{c}\text { Year of } \\
\text { construction }\end{array}$ & $\begin{array}{c}\text { Space-planning } \\
\text { solution }\end{array}$ & $\begin{array}{c}\text { Material and } \\
\text { structure of } \\
\text { partitions }\end{array}$ & $\begin{array}{c}\text { Gap to } \\
\text { current } \\
\text { space- } \\
\text { planning } \\
\text { requirements }\end{array}$ \\
\hline $\mathrm{RB}_{1}$ & $\mathrm{X}_{11}$ & $\mathrm{X}_{12}$ & $\mathrm{X}_{13}$ & $\mathrm{X}_{14}$ \\
\hline $\mathrm{RB}_{2}$ & $\mathrm{X}_{21}$ & $\mathrm{X}_{22}$ & $\mathrm{X}_{23}$ & $\mathrm{X}_{24}$ \\
\hline $\mathbf{m}$ & $\boldsymbol{\cdots}$ & $\boldsymbol{\cdots}$ & $\mathbf{\cdots}$ & $\mathbf{\cdots}$ \\
\hline $\mathrm{RBm}$ & $\mathrm{X}_{\mathrm{m} 1}$ & $\mathrm{X}_{\mathrm{m} 2}$ & $\mathrm{X}_{\mathrm{m} 3}$ & $\mathrm{X}_{\mathrm{m} 4}$ \\
\hline
\end{tabular}

Tables 3 and 4 are the matrix form of initial data presentation for cluster analysis problems.

In accordance with [22-23], the solution of this problem lies in determination of natural stratification of observations into well-defined clusters being at some distance from each other. When clusters are formed, different measures of distance between cluster elements and clusters themselves can be used [22-23]. Nowadays, the following types of distance measures are used. 
1. Euclidean distance.

$$
P=\sqrt{\sum_{i=1}^{N}}(A i-B i)^{2}
$$

where $\mathrm{P}$ - distance between objects $\mathrm{A}$ and $\mathrm{B} ; \mathrm{A}_{\mathrm{i}}$ - value of property $\mathrm{i}$ of object $\mathrm{A} ; \mathrm{B}_{\mathrm{i}}-$ value of property i of object B.

2. Squared Euclidean distance.

$$
P=\sum_{i=1}^{N}(A i-B i)^{2}
$$

where $\mathrm{P}$ - distance between objects $\mathrm{A}$ and $\mathrm{B} ; \mathrm{A}_{\mathrm{i}}$ - value of property $\mathrm{i}$ of object $\mathrm{A} ; \mathrm{B}_{\mathrm{i}}-$ value of property i of object $B$.

3. Weighted Euclidean distance.

$$
P=\sqrt{\sum_{i=1}^{N} w_{i}}(A i-B i)^{2}
$$

where $\mathrm{P}$ - distance between objects $\mathrm{A}$ and $\mathrm{B} ; \mathrm{A}_{\mathrm{i}}$ - value of property $\mathrm{i}$ of object $\mathrm{A} ; \mathrm{B}_{\mathrm{i}}-$ value of property i of object $\mathrm{B}, w_{i}-$ "weight" of property $i$.

Formula (4) is the most practical for forming of specific objects' clusters; it takes into account the significance of each property of the objects under consideration.

Thus, when the notion of distance between objects and clusters is defined, the optimization problem of finding of groups of objects with the minimum possible distance between objects in groups and the maximum possible distances between groups can be formulated The problems of such type can be solved by the "nearest neighbor" method. There are also other methods to solve such problems [22-23].

The methodological approach to classification of specific objects at urban areas for their further renovation can be generalized in the form of a flow chart given in Figure 3.

1. Breakdown of compact built-up development areas into separate CPFs as per their natural borders: roads, tree belts, water barriers, etc. to obtain a certain breakdown variant $\mathrm{m}$, which includes a set of $\mathrm{n} C P F$ units, where $\mathrm{n}=\overline{1, \mathrm{~N}} 1 \mathrm{~m}$

2. Determination of a number or one CPF with the lowest TC indicators and, consequently, increased D and (or) $\mathrm{O}$ indicators.

3. Selection of specific objects out of CPFs determined, forming a CPF with low TC estimates, i.e. with the highest values of $\mathrm{D}$ and (or) $\mathrm{O}$.

4. Selection of activities, technical and engineering solutions for renovation of specific objects of CPF, assuring the reduction of their D and (or) O and transformation to "good" or "perfect" condition.

5. Selection of factors being the classification features for specific objects under consideration.

6. Grouping of specific objects into classes based on a number of matching classification features.

Fig. 3. Flow chart of methodological approach to evaluation and classification of specific objects at compact built-up development areas. 


\section{Conclusions}

1. The application of systematic approach to classification of CBDA has been justified, which makes it possible to select efficient organizational and engineering solutions on renovation of these areas.

2. It has been suggested to classify CBDA presented in the form of a system - CPF - and its components and objects as per their level of technical comfort, depreciation and obsolescence.

3. The methodological approach to classification of specific objects of CPFs - buildings, utilities, municipal structures, etc. - based on structural, materials-related, space-planning characteristics, degree of deterioration of separate elements and other uniform characteristics has been developed for renovation of these objects with the help of one-type organizational and engineering solutions, constructional materials and structures, machines and equipment, reconstruction and repair methods.

\section{References}

1. A.A. Gusakov, System Engineering in Construction (Stroyizdat, Moscow, 1993)

2. I.M. Smoliar, Urban Planning as a System: Forecasting, Programming, Designing (Editorial URSS, Moscow, 2001)

3. A.A. Gusakov, System Engineering (New Millennium Fund, Moscow, 2002)

4. A.A. Gusakov, Industrial and Civil Construction, 12 (2000)

5. V.A. Pliner, Systematic Approach in Designing and Arrangement of New Cities (Stroyizdat, Moscow, 1985)

6. S.I. Matreninskiy, Bulletin of Voronezh State Architectural and Construction Institute, Construction and Architecture 1(29), 49-57 (2013)

7. A.E. Semechkin, A.A. Gusakov, System Analysis of Reconstruction of Urban Areas. In: System Engineering (New Millennium Fund, Moscow, 2002)

8. K.A. Shreiber, Technology and Organization of Repairs and Construction. Scientific publication (ACV Publishing House, Moscow, 2008)

9. A.A. Volkov, A.A. Gusakov, Homeostat of Construction Projects. In: System Engineering (New Millennium Fund, Moscow, 2002)

10. S.I. Matreninskiy, E.M. Chernyshov, Bulletin of the central regional department of the Russian academy of architecture and construction sciences 7, 33-48 (2008)

11. S.I. Matreninskiy, V.Y. Mischenko, E.M. Chernyshov, Proceedings of the 3th International Conference on Sustainable Cities, Urban Sustainability and Transportation (SCUST14), 9-17 (2014)

12. S. Matreninskiy, V. Mischenko, E. Chernyshov, International Journal of Energy and Environment 9, 32-43 (2015)

13. S.I. Matreninskiy, V.Y. Mischenko, I.E. Spivak, K.Y. Zubenko, Industrial and Civil Construction 11, 59-62 (2008)

14. S.I. Matreninskiy, V.Y. Mischenko, I.E. Spivak, Industrial and Civil Construction 12, 54-56 (2008)

15. S.I. Matreninskiy, V.Y. Mischenko, I.E. Spivak, WSEAS Transactions on Environment and Development 12, 108-117 (2016)

16. S.I. Matreninskiy, V.Y. Mischenko, Le Trong Hai, E.A. Solnstev, Industrial and Civil Construction 1, 31-34 (2010) 
17. S. Matreninskiy, V. Mischenko, 4th NAUN International Conference on Energy Systems, Environment, Entrepreneurship and Innovation (ICESEEI15), 18-23 (2015)

18. S. Matreninskiy, V. Mischenko, Proceedings of the International Conference on Economics and Business Administration (EBA 2015), 84-90 (2015)

19. S. Matreninskiy, V. Mischenko, Proceedings of the 5th International Conference on Urban Sustainability, ultural Sustainability, Green Development, Green Structures and Clean Cars (USCUDAR '14), 58-63 (2014)

20. E.C. Harrington, Quality Control 21(10), 494-498 (1965)

21. S. Matreninskiy, V. Mischenko, I. Spivak, Proceedings of the 8th International Conference on Energy Planning, Energy Saving, Environmental Education (EPESE '15), 70-75 (2015)

22. I.D. Mandel, Cluster Analysis (Finance and Statistics, Moscow, 1988)

23. S.A. Aivazyan, V.M. Bukhshtaber, I.S. Enyukov, L.D. Meshalkin, Applied Statistics: Classification and Dimension Decreasing (Finance and Statistics, Moscow, 1989) 